\title{
Interference Assessment of Various Endogenous and Exogenous Substances on the Performance of the Eversense Long-Term Implantable Continuous Glucose Monitoring System
}

\author{
Carrie Lorenz, PhD, Wendolyn Sandoval, MS, and Mark Mortellaro, PhD
}

\begin{abstract}
Background: A variety of prescriptions and over-the-counter medications interfere with transcutaneous continuous glucose monitoring (CGM) sensors. This study characterized the interference profile of the Eversense ${ }^{\circledR}$ CGM System (Senseonics, Inc., Germantown, MD), which has a different mechanism of glucose detection than other CGM systems.

Materials and Methods: Sensor bias (sensor glucose concentration measurement - plasma glucose concentration measured by a reference test) was measured in vitro against 41 different substances at supratherapeutic/ supraphysiologic plasma concentrations. Testing was performed using a paired-sample method adapted from the Clinical and Laboratory Standards Institute guidance document EP7-A2. Any substance producing sensor bias that exceeded the International Organization for Standardization (ISO) document 15197:2013 limits was then tested using an in vitro dose-response method to determine whether the concentration producing a significant sensor bias was within physiologic/therapeutic concentration ranges.

Results: Eight of 41 substances produced a sensor bias that exceeded ISO 15197:2013 limits when tested in vitro at supratherapeutic/supraphysiologic plasma concentrations. Only two of these substances (tetracycline and mannitol) exceeded bias limits within therapeutic concentration ranges. Notably, neither acetaminophen nor ascorbic acid, which are substances reported to interfere with other CGM systems, produced sensor bias that exceeded ISO limits when used at physiologic concentrations.

Conclusions: Although tetracycline and mannitol interfered with the Eversense sensor, substances frequently reported to interfere with enzymatic, electrochemical-based transcutaneous CGM systems, such as acetaminophen and ascorbic acid, did not affect Eversense readings.
\end{abstract}

Keywords: Continuous glucose monitoring, Sensor, Drug interferences.

\section{Introduction}

$\mathbf{C}$ LINICAL USE of continuous glucose monitoring (CGM) systems is associated with reduced hemoglobin Alc values, ${ }^{1-3}$ decreased exposure to hypoglycemia, ${ }^{4,5}$ reduced glycemic variability, ${ }^{6}$ and enhanced convenience and quality of life. ${ }^{7,8}$ However, just as the presence of certain exogenous and endogenous substances in the blood can interfere with the accuracy of traditional (i.e., fingerstick) blood glucose me- ters, ${ }^{9-11}$ the presence of such substances in the interstitial fluid (ISF) may also interfere with the accuracy of CGM systems and result in a falsely high or low report of glucose values. ${ }^{12-14}$

Studies have suggested that various substances including ascorbic acid (vitamin C), acetaminophen, dopamine, maltose, xylose, and mannitol may interfere with the function of electrochemical glucose sensors. ${ }^{9-12,15,16}$ Vitamin $C$ and acetaminophen are of particular concern as they are very commonly used over-the-counter medications and hence may

\footnotetext{
Senseonics, Incorporated, Germantown, Maryland.
}

(C) Carrie Lorenz, et al., 2018; Published by Mary Ann Liebert, Inc. This Open Access article is distributed under the terms of the Creative Commons Attribution Noncommercial License (http://creativecommons.org/licenses/by-nc/4.0/) which permits any noncommercial use, distribution, and reproduction in any medium, provided the original author(s) and the source are credited. 
be taken without medical supervision. Furthermore, physicians are frequently unaware of their patients' nonprescription medication use, ${ }^{17,18}$ and these substances are available as or incorporated into a variety of branded or combination product over-the-counter analgesics, cold remedies, or supplement formulations. Users may be unaware that they are ingesting the specific substances against which they may have been counseled ${ }^{19}$ or that they may inadvertently take doses that exceed recommended amounts. ${ }^{20}$

The novel Eversense ${ }^{\circledR}$ CGM System (Senseonics, Inc., Germantown, MD) utilizes a fully subcutaneously implantable glucose sensor (Fig. 1) whose accuracy and clinical utility for 90- and 180-day periods have been validated in prospective, multisite clinical trials. ${ }^{21,22}$ Although substances such as ascorbic acid, acetaminophen, dopamine, maltose, xylose, and mannitol can interfere with CGM systems that use electrochemical- and enzymatic- (i.e., glucose oxidase and glucose dehydrogenase) based methods to measure glucose concentrations, $9,11,12,15,23-25$ the Eversense CGM sensor uses an abiotic (non-enzyme based), fluorescent glucose-indicating polymer to measure glucose ${ }^{26}$ (Fig. 2) and, therefore, may have a different drug interference profile. Electrochemical enzymatic-based sensors are potentially subject to interference from substances (e.g., acetaminophen) that may electrochemically react at the sensor working electrode or that may exhibit cross-reactivity with the enzyme. The Eversense sensor does not contain an electrode or an enzyme and is, therefore, not subject to those specific interference mechanisms. Rather, substances that may bind to the Eversense sensor polymer or that may absorb or fluoresce light over the spectral operating range of the sensor could potentially interfere with sensor glucose readings. Therefore, the goal of this study was to use commonly accepted in vitro test methods $^{27}$ to assess the potential for various substances to interfere with Eversense CGM sensor glucose measurements.

\section{Materials and Methods}

An in vitro screening study was performed to assess the potential for various endogenous and exogenous sub- stances to interfere with the accuracy of the Eversense CGM sensor.

\section{Selection of substances for in vitro interference testing}

The Eversense CGM sensor uses an abiotic, fluorescent glucose-indicating polymer (a hydrogel) that is formed onto the surface of the sensor housing (Fig. 1) to measure glucose concentrations. $^{26}$ The fundamental recognition reaction is a reversible condensation of the cis-diol groups of glucose with the bis-boronate moieties of the indicator polymer. Glucose binding at the boronic acids disrupts intramolecular fluorescence quenching (from the indicator amine groups), resulting in an increase in fluorescence intensity without chemically altering the indicator molecule. This photo-induced electron transfer quenching transduction mechanism has been described in other reports. ${ }^{26,28}$ The boronic acids groups are spatially placed to form a glucose-sized binding cleft ${ }^{28}$ (Fig. 2). Vicinal diol (two adjacent hydroxyl groups)-containing molecules, particularly those structurally related to glucose, have the highest likelihood of exhibiting cross-reactivity, ${ }^{28}$ and, therefore, substances from the various classes of vicinal diols (i.e., monosaccharides, disaccharides, polysaccharides, sugar alcohols, catechols, alpha-hydroxy carboxylic acids, and aminosugars) were selected for interference testing (Table 1).

Furthermore, glucose binding results in an increase in fluorescence intensity from the glucose-indicating polymer anthracene moieties. ${ }^{26}$ The sensor contains a light-emitting diode as indicator excitation source and two filtered photodiodes to measure fluorescence intensity (Fig. 1). ${ }^{26}$ Therefore, representative substances (e.g., levofloxacin, piroxicam, tetracycline, and quinidine) that absorb or fluoresce light over wavelength ranges that overlap with anthracene absorption or fluorescence were also selected for interference testing. ${ }^{29}$

The remaining substances selected for interference testing included several common medications prescribed for the treatment of diabetes, ${ }^{30}$ substances examined in prior studies of glucose interference testing, ${ }^{12,23-25,31}$ and those outlined in International Organization for Standardization (ISO) document 15197:2013 ("In vitro diagnostic test systems-

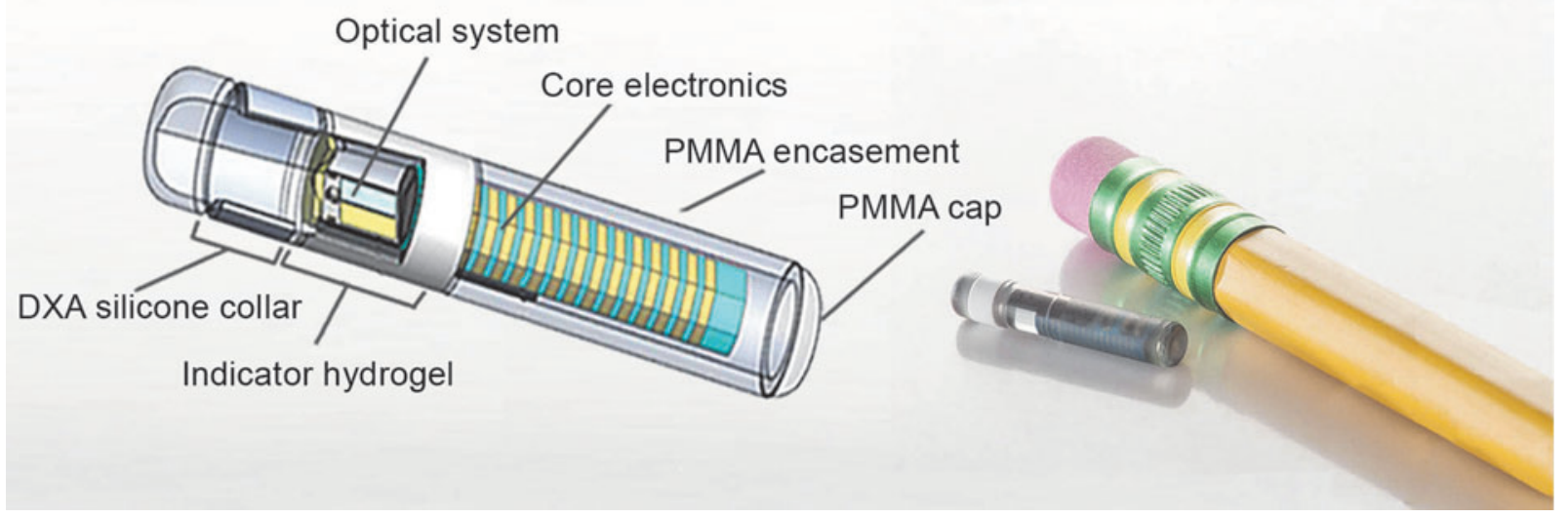

FIG. 1. Eversense ${ }^{\circledR}$ implantable glucose sensor. DXA, dexamethasone acetate; PMMA, poly(methyl methacrylate). 


\section{Indicator group within polymer}

\section{Glucose bound to indicator}

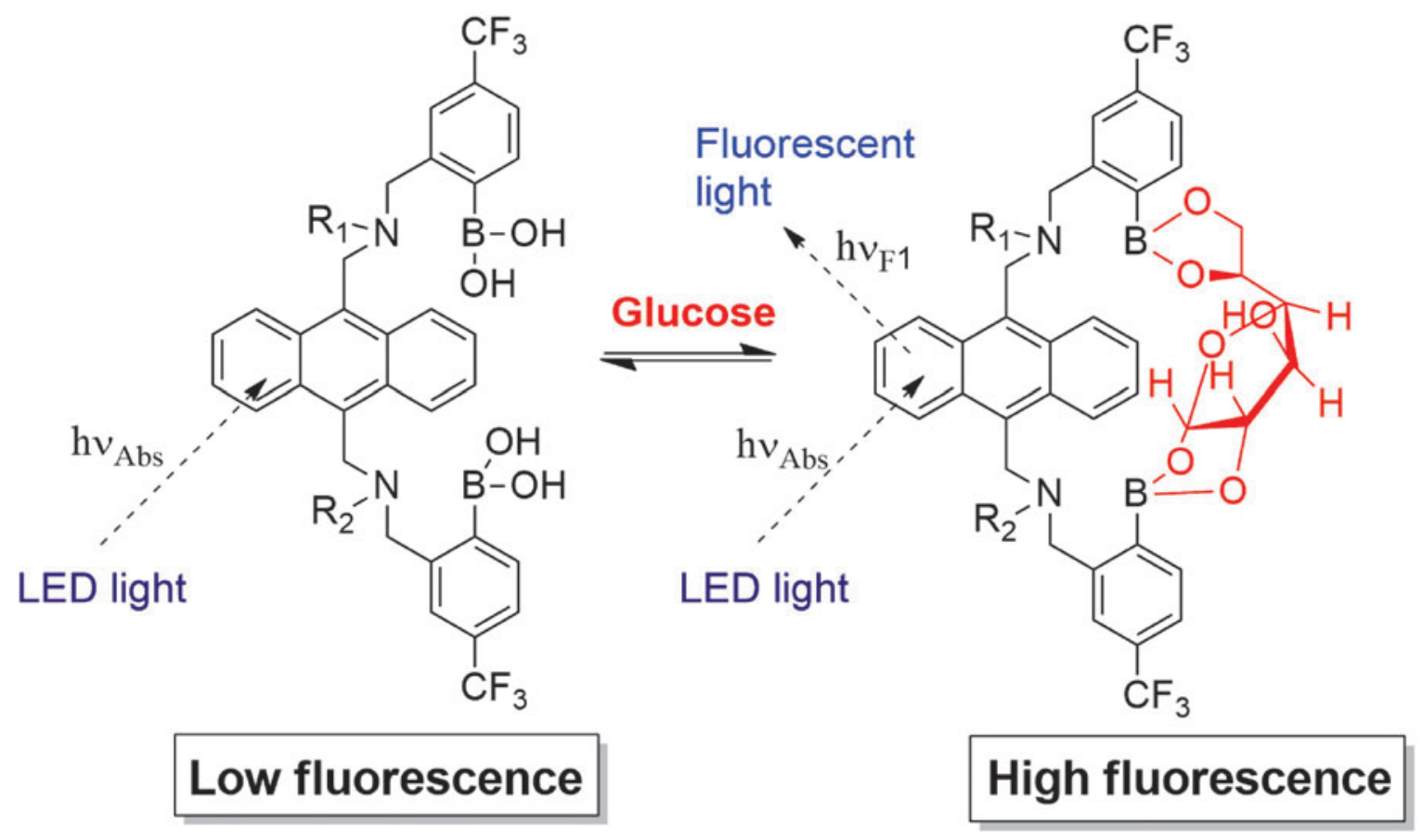

FIG. 2. Equilibrium binding of glucose to the glucose indicating polymer and effects on fluorescence. $\mathrm{R}_{2}$ denotes connectivity to the indicator polymer backbone. ${ }^{26}$ LED, light-emitting diode.

requirements for blood glucose monitoring systems for selftesting in managing diabetes mellitus"') ${ }^{32}$ or U.S. Food and Drug Administration (FDA) Guidance Document for Blood Glucose Monitoring Test Systems. ${ }^{10}$ Because the Eversense CGM sensor is inserted in the subcutaneous space, endogenous species that remain intracellularly localized to blood cells and that do not enter the interstitial space, such as hemoglobin, were not tested as potential interferents.

A full list of the 41 substances (23 exogenous substances, 18 endogenous substances) that were tested is included in Table 1.

\section{In vitro interference testing}

The Eversense CGM sensor measures glucose in aqueous media (ISF) when inserted in subcutaneous tissue. ${ }^{22,26,33,34}$ In vitro tests were performed in model solutions composed of phosphate-buffered saline $(10 \mathrm{mM}$ phosphate buffer solution, $\mathrm{NaH}_{2} \mathrm{PO}_{4}-\mathrm{H}_{2} \mathrm{O}=1.90 \mathrm{mM}, \mathrm{Na}_{2} \mathrm{HPO}_{4}-12 \mathrm{H}_{2} \mathrm{O}=8.10 \mathrm{mM}$, $\mathrm{NaCl}=138 \mathrm{mM}, \quad \mathrm{KCl}=2.7 \mathrm{mM}$, and ethylenediaminetetraacetic acid $=1 \mathrm{mM}$ adjusted to $\mathrm{pH} 7.4$ with $\mathrm{HCl}$ or $\mathrm{NaOH}$ ) and bovine serum albumin $(22 \mathrm{mg} / \mathrm{mL})$ that mimic the salt and protein concentrations typical of subcutaneous ISF. ${ }^{35,36}$ All tests were performed at two different glucose concentrations ( $\sim 77$ and $321 \mathrm{mg} / \mathrm{dL}$ ), except for the sugar alcohols, which were tested at three different concentrations $(54,108$, and $270 \mathrm{mg} / \mathrm{dL}$ ) in response to the recently released FDA Guidance Document for Blood Glucose Monitoring Test Systems. ${ }^{10}$ A YSI 2300 STAT Plus glucose analyzer (YSI Life Sciences, Yellow Springs, $\mathrm{OH}$ ) was used to obtain reference glucose measurements. Tests were conducted in the presence and absence of the potential interfering substance. The concentration at which each added substance was tested for having an interfering effect was based on the guidelines provided in the Clinical and Laboratory Standards Institute (CLSI) document EP7-A2 section 5.5 "Interferent Test Concentrations"; these recommended concentrations vary according to the specific substance, but all substances were tested at a concentration above the highest plasma concentration expected in the intended patient population. ${ }^{27}$

Custom test fixtures, each containing a 500 -mL fluid reservoir (maintained at $37^{\circ} \mathrm{C}$ ) and capable of measuring data from up to 25 sensors at a time, were used. A paired-sample test design was used in which measurements obtained for each sensor in solutions without potential interferent ("control solution") were compared with measurements obtained in solutions with the potential interferent ("test solution"). Sensors were equilibrated in each solution for 30-60 min at $37 \pm 1^{\circ} \mathrm{C}$ before sensor data collection.

CGM sensor and YSI reference glucose measurements were obtained for each test condition (i.e., substance and glucose concentration). Data were calculated using the mean of a minimum of 40 sensors (from at least three sensor lots) based on an average of seven readings for each sensor in each test condition. Results at each test concentration were averaged. A test substance was considered to have an interfering effect if test samples met either of the following performance criteria as defined by ISO 15197:2013: (1) for solution glucose concentrations $<5.55 \mathrm{mmol} / \mathrm{L}(<100 \mathrm{mg} / \mathrm{dL})$, the average difference in sensor glucose measurements between the test sample and the control sample ("sensor bias") exceeded $0.55 \mathrm{mmol} / \mathrm{L}(10 \mathrm{mg} / \mathrm{dL})$; or (2) for solution glucose 
Table 1. Eversense Continuous Glucose Monitoring Sensor Performance

When Tested in the Presence of Possible Interferents at Supraphysiologic/Therapeutic Concentrations and Multiple Glucose Concentrations

\begin{tabular}{|c|c|c|c|c|}
\hline Substance & $\begin{array}{l}\text { Maximum physiologic } \\
\text { or therapeutic } \\
\text { plasma concentration } \\
{[\mathrm{mg} / \mathrm{dL}(\mathrm{mmol} / \mathrm{L})]^{\mathrm{a}}}\end{array}$ & $\begin{array}{c}\text { Substance } \\
\text { concentration } \\
\text { tested } \\
{[\mathrm{mg} / \mathrm{dL}(\mathrm{mmol} / \mathrm{L})]}\end{array}$ & $\begin{array}{c}\text { Glucose } \\
\text { concentrations } \\
\text { tested } \\
{[\mathrm{mg} / \mathrm{dL}(\mathrm{mmol} / \mathrm{L})]}\end{array}$ & $\begin{array}{c}\text { Eversense CGM } \\
\text { sensor bias } \\
{[\mathrm{mg} / \mathrm{dL}} \\
(\mathrm{mmol} / \mathrm{L}) \text { or } \%]^{\mathrm{b}}\end{array}$ \\
\hline \multicolumn{5}{|c|}{ Endogenous and exogenous substances: } \\
\hline Acetaminophen & $3.0(0.2)$ & $20(1.3)$ & $\begin{array}{c}74(4.1) \\
317(17.6)\end{array}$ & $\begin{array}{c}-8.7(-0.48) \\
-8.3 \%\end{array}$ \\
\hline Amoxicillin & $2.5(0.068)$ & $7.5(0.2)$ & $\begin{aligned} 77 & (4.3) \\
321 & (17.8)\end{aligned}$ & $\begin{array}{c}-4.3(-0.24) \\
-4.7 \%\end{array}$ \\
\hline Ascorbic acid & $2.0(0.114)$ & $6.0(0.34)$ & $\begin{array}{c}76(4.2) \\
321(17.8)\end{array}$ & $\begin{array}{c}7.7(0.43) \\
0.1 \%\end{array}$ \\
\hline Caffeine & $2(0.103)$ & $6.0(0.308)$ & $\begin{array}{c}76(4.2) \\
327(18.1)\end{array}$ & $\begin{array}{c}-3.6(-0.20) \\
-3.8 \%\end{array}$ \\
\hline Creatinine & $1.3(0.115)$ & $5(0.442)$ & $\begin{array}{c}76(4.2) \\
315(17.5)\end{array}$ & $\begin{array}{c}-3.6(-0.20) \\
-1.9 \%\end{array}$ \\
\hline Dopamine & $0.03(0.00196)$ & $0.09(0.00587)$ & $\begin{array}{c}72(4.0) \\
304(16.9)\end{array}$ & $\begin{array}{c}-2.1(-0.12) \\
0.5 \%\end{array}$ \\
\hline EDTA & NA & $0.1(0.0034)$ & $\begin{array}{r}78(4.3) \\
335(18.6)\end{array}$ & $\begin{array}{c}-2.8(-0.16) \\
-6.3 \%\end{array}$ \\
\hline Ephedrine & $0.02(0.001)^{25}$ & $0.50(0.03)$ & $\begin{array}{c}77(4.3) \\
318(17.7)\end{array}$ & $\begin{array}{c}-2.4(-0.13) \\
5.1 \%\end{array}$ \\
\hline Gentisic acid & $0.6(0.039)$ & $1.8(0.117)$ & $\begin{array}{c}75(4.1) \\
315(17.5)\end{array}$ & $\begin{array}{c}-7.7(-0.43) \\
-8.5 \%\end{array}$ \\
\hline Glutathione & $32(1.05)$ & $92(3)$ & $\begin{aligned} 76 & (4.2) \\
322 & (17.9)\end{aligned}$ & $\begin{array}{c}-2.4(-0.14) \\
-1.3 \%\end{array}$ \\
\hline Glyburide (glibenclamide) & $0.06(0.0013)$ & $0.2(0.00389)$ & $\begin{array}{c}76(4.2) \\
320(17.8)\end{array}$ & $\begin{array}{c}-3.5(-0.20) \\
-0.4 \%\end{array}$ \\
\hline Heparin & $100 \mu / \mathrm{dL}$ & $300 \mathrm{U} / \mathrm{dL}$ & $\begin{array}{c}76(4.2) \\
318(17.7)\end{array}$ & $\begin{array}{c}-5.1(-0.29) \\
-4.6 \%\end{array}$ \\
\hline Ibuprofen & $7.0(0.34)$ & $50(2.425)$ & $\begin{aligned} 78 & (4.3) \\
328 & (18.2)\end{aligned}$ & $\begin{array}{c}-3.8(-0.21) \\
-4.6 \%\end{array}$ \\
\hline Lactate & $20(2.2)$ & $60(6.6)$ & $\begin{array}{c}76(4.2) \\
317(17.6)\end{array}$ & $\begin{array}{c}-11.5(-0.64) \\
-9.5 \%\end{array}$ \\
\hline L-DOPA & $0.4(0.02)^{42,43}$ & $1.2(0.06)$ & $\begin{array}{r}77(4.3) \\
325(18.1)\end{array}$ & $\begin{array}{c}-20(-1.1) \\
-11 \%\end{array}$ \\
\hline Levofloxacin & $0.6(0.162)$ & $1.8(0.0486)$ & $\begin{array}{c}77(4.3) \\
318(17.7)\end{array}$ & $\begin{array}{c}-2.8(-0.16) \\
-0.2 \%\end{array}$ \\
\hline Metformin & $0.4(0.031)$ & $4(0.31)$ & $\begin{array}{c}80(4.4) \\
331(18.4)\end{array}$ & $\begin{array}{c}-3.5(-0.19) \\
-0.4 \%\end{array}$ \\
\hline Methyl-DOPA & $0.75(0.0355)$ & $1.5(0.071)$ & $\begin{aligned} 78 & (4.3) \\
319 & (17.7)\end{aligned}$ & $\begin{array}{c}-9.5(-0.53) \\
-5.5 \%\end{array}$ \\
\hline Naproxen & $12(0.52)$ & $50(2.17)$ & $\begin{array}{c}76(4.2 \\
321(17.8)\end{array}$ & $\begin{array}{c}7.7(0.43) \\
0.1 \%\end{array}$ \\
\hline Piroxicam & $0.8(0.002)$ & $6(0.181)$ & $\begin{array}{c}76(4.2) \\
321(17.8)\end{array}$ & $\begin{array}{c}-56(-3.1) \\
-47 \%\end{array}$ \\
\hline Pralidoxime iodide (PAM) & $3.8(0.22)^{44}$ & $127(4.76)$ & $\begin{array}{c}75(4.2) \\
317(17.6)\end{array}$ & $\begin{array}{c}-46(-2.54) \\
-38 \%\end{array}$ \\
\hline Quinidine & $0.6(0.0185)$ & $1.2(0.037)$ & $\begin{array}{c}77(4.3) \\
324(18.0)\end{array}$ & $\begin{array}{c}-2.1(-0.12) \\
2.3 \%\end{array}$ \\
\hline Salicyclic acid & $30(2.17)$ & $60(4.34)$ & $\begin{array}{r}80(4.5) \\
326(18.1)\end{array}$ & $\begin{array}{c}-54(-3.0) \\
-55 \%\end{array}$ \\
\hline Tetracycline & $0.5(0.0113)$ & $1.5(34)$ & $\begin{array}{c}78(4.3) \\
327(18.2)\end{array}$ & $\begin{array}{c}-62(-3.4) \\
-61 \%\end{array}$ \\
\hline Tolazamide & $3.4(0.11)^{45}$ & $10.3(0.33)$ & $\begin{array}{c}82(4.5) \\
321(17.8)\end{array}$ & $\begin{array}{c}-4.9(-0.27) \\
-4.7 \%\end{array}$ \\
\hline Tolbutamide & $10.8(0.4)$ & $65(2.4)$ & $\begin{array}{r}77(4.3) \\
322(17.9)\end{array}$ & $\begin{array}{c}-3.8(-0.21) \\
-4.0 \%\end{array}$ \\
\hline Urea & $86(14.3)$ & $258(42.9)$ & $\begin{aligned} 79 & (4.4) \\
328 & (18.2)\end{aligned}$ & $\begin{array}{c}-6.0(-0.33) \\
-6.4 \%\end{array}$ \\
\hline
\end{tabular}


TABle 1. (CONTINUED)

\begin{tabular}{|c|c|c|c|c|}
\hline Substance & $\begin{array}{c}\text { Maximum physiologic } \\
\text { or therapeutic } \\
\text { plasma concentration } \\
{[\mathrm{mg} / \mathrm{dL}(\mathrm{mmol} / \mathrm{L})]^{\mathrm{a}}}\end{array}$ & $\begin{array}{c}\text { Substance } \\
\text { concentration } \\
\text { tested } \\
{[\mathrm{mg} / \mathrm{dL}(\mathrm{mmol} / \mathrm{L})]}\end{array}$ & $\begin{array}{c}\text { Glucose } \\
\text { concentrations } \\
\text { tested } \\
{[\mathrm{mg} / \mathrm{dL}(\mathrm{mmol} / \mathrm{L})]}\end{array}$ & $\begin{array}{c}\text { Eversense CGM } \\
\text { sensor bias } \\
{[\mathrm{mg} / \mathrm{dL}} \\
(\mathrm{mmol} / \mathrm{L}) \text { or } \%]^{\mathrm{b}}\end{array}$ \\
\hline \multicolumn{5}{|c|}{ Non-glucose sugars: } \\
\hline Fructose & $6.0(0.133)$ & $18(1.0)$ & $\begin{array}{c}94(5.2) \\
328(18.2)\end{array}$ & $\begin{array}{c}-6.1(-0.34) \\
-8.8 \%\end{array}$ \\
\hline Galactose & $<6.0(0.28)$ & $15(0.84)$ & $\begin{array}{r}73(4.1) \\
318(17.7)\end{array}$ & $\begin{array}{c}-2.7(-0.15) \\
-2.0 \%\end{array}$ \\
\hline Lactose & $0.5(0.015)^{25}$ & $20(0.58)$ & $\begin{aligned} 75 & (4.2) \\
322 & (17.9)\end{aligned}$ & $\begin{array}{c}-3.7(-0.20) \\
-5.5 \%\end{array}$ \\
\hline Maltose & $120(3.5)^{46}$ & $200(5.8)$ & $\begin{array}{r}76(4.2) \\
315(17.5)\end{array}$ & $\begin{array}{c}-2.4(-0.13) \\
-1.3 \%\end{array}$ \\
\hline Mannose & $1.5(0.08)^{47}$ & $3.8(0.21)$ & $\begin{aligned} 77 & (4.3) \\
323 & (18.0)\end{aligned}$ & $\begin{array}{c}-4.1(-0.23) \\
-4.0 \%\end{array}$ \\
\hline Ribose & $32(2)^{48}$ & $135(9)$ & $\begin{array}{c}79(4.4) \\
317(17.6)\end{array}$ & $\begin{array}{c}-9.1(-0.50) \\
-24 \%\end{array}$ \\
\hline Xylose & $54(3.6)^{49}$ & $180(12)$ & $\begin{aligned} 77 & (4.3) \\
317 & (17.6)\end{aligned}$ & $\begin{array}{c}6.1(0.34) \\
-9.1 \%\end{array}$ \\
\hline \multicolumn{5}{|c|}{ Sugar alcohols: } \\
\hline Erythritol ${ }^{\mathrm{c}}$ & \multicolumn{2}{|c|}{$0.09(0.0074)$} & $\begin{aligned} 57 & (3.2) \\
129 & (7.2) \\
285 & (15.8)\end{aligned}$ & $\begin{array}{c}-0.6(-0.04) \\
-2 \% \\
-1 \%\end{array}$ \\
\hline Isomalt $^{\mathrm{c}}$ & \multicolumn{2}{|c|}{$0.09(0.0026)$} & $\begin{aligned} 55(3.0) \\
124(6.9) \\
268(14.9)\end{aligned}$ & $\begin{array}{c}-0.3(-0.02) \\
-2 \% \\
-0.2 \%\end{array}$ \\
\hline Lactitol $^{\mathrm{c}}$ & \multicolumn{2}{|c|}{$0.09(0.0026)$} & $\begin{aligned} & 56(3.1) \\
& 122(6.8) \\
& 263(14.6)\end{aligned}$ & $\begin{array}{c}-0.5(-0.03) \\
-2 \% \\
-0.02 \%\end{array}$ \\
\hline Maltitol $^{\mathrm{c}}$ & \multicolumn{2}{|c|}{$0.09(0.0026)$} & $\begin{aligned} 56 & (3.1) \\
124 & (6.9) \\
264 & (14.7)\end{aligned}$ & $\begin{array}{c}-0.8(-0.04) \\
-1 \% \\
1 \%\end{array}$ \\
\hline Mannitol $^{\mathrm{d}}$ & $34^{38}$ & $98(0.0049)$ & $\begin{array}{c}75(4.1) \\
317(17.6)\end{array}$ & $\begin{array}{c}183(10.2) \\
33 \%\end{array}$ \\
\hline Mannitol $^{\mathrm{c}}$ & \multicolumn{2}{|c|}{$0.09(0.0049)$} & $\begin{aligned} 54 & (3.0) \\
124 & (6.9) \\
275 & (15.3)\end{aligned}$ & $\begin{array}{c}-0.4(-0.02) \\
-1 \% \\
-0.01 \%\end{array}$ \\
\hline Sorbitol $^{\mathrm{c}}$ & \multicolumn{2}{|c|}{$0.09(0.0049)$} & $\begin{aligned} & 55(3.0) \\
& 123(6.8) \\
& 268(14.9)\end{aligned}$ & $\begin{array}{c}-0.5(-0.03) \\
-2 \% \\
0.3 \%\end{array}$ \\
\hline Xylitol $^{\mathrm{c}}$ & \multicolumn{2}{|c|}{$0.09(0.0059)$} & $\begin{aligned} 57 & (3.1) \\
127 & (7.0) \\
281 & (15.6)\end{aligned}$ & $\begin{array}{c}-0.9(-0.05) \\
-2 \% \\
-2 \%\end{array}$ \\
\hline
\end{tabular}

Rows highlighted in gray are substances that exceeded interference test bias limits.

abtained from EP7-A2 unless otherwise indicated by reference.

${ }^{\mathrm{b}}$ Bias reported as percentage at glucose test concentrations $>100 \mathrm{mg} / \mathrm{dL}(5.5 \mathrm{mmol} / \mathrm{L})$.

${ }^{c}$ Tested at the concentration specified by FDA Guidance document for Blood Glucose Monitoring Test Systems.

${ }^{\mathrm{d}}$ See the Discussion section for discussion of mannitol tests.

CGM, continuous glucose monitoring; EDTA, ethylenediaminetetraacetic acid; FDA, U.S. Food and Drug Administration; NA, not available.

concentrations $\geq 5.55 \mathrm{mmol} / \mathrm{L}(\geq 100 \mathrm{mg} / \mathrm{dL})$, the average difference in sensor glucose measurements between the test sample and the control sample exceeded $10 \%$.

Substances identified as having an interfering effect were further tested using an in vitro dose-response method derived from the CLSI document EP7-A2. ${ }^{27}$ Dose-response testing typically used three times the therapeutic plasma concentration as the highest concentration tested and $\sim 0 \%, 25 \%, 50 \%$, and $75 \%$ of that concentration as intermediate test points to generate a curve. The order at which these concentrations were tested was varied to avoid any confounding effects. Least squares regression was used to fit the data to a doseresponse function and to determine the concentration at which the interferent exceeded the bias limits stated in ISO 15197:2013. ${ }^{32}$ The Minitab 17 software package (Minitab, Inc., State College, PA) was used to process the data, plot curves with response functions, and calculate $95 \%$ confidence intervals around the means. A minimum of 30 sensors from at least three production lots were used for each test.

\section{Results}

\section{In vitro screening study}

Of the 41 substances tested, eight were identified as potential interferents (i.e., sensor bias exceeded the ISO bias limit) when tested at a concentration substantially more than 
the highest plasma concentration expected in the intended patient population (Table 1). Most of the exogenous interfering substances identified within this screening experiment were prescription medications (L-DOPA, piroxicam, pralidoxime iodide, and tetracycline), but one of the interferents, salicylic acid (aspirin), is widely available over the counter. The remainder of interferents comprised endogenous substances (i.e., ribose and lactate) and the nonglucose sugar, mannitol.

\section{In vitro dose-response study}

Because the screening experiment was performed with supratherapeutic or supraphysiologic plasma concentrations of the substances, the eight substances identified in the screening study were further assessed in an in vitro doseresponse study to determine the substance concentration required to reach the sensor bias limit. This concentration was then compared with the maximum therapeutic/physiologic plasma concentration (or, when available in the published literature, the interstitial concentration reported from approved dosing regimens) to assess whether it could represent a clinically relevant sensor interferent. The Eversense sensor is designed for implantation in the subcutaneous space, just beneath the skin, and, therefore, interstitial concentrations, not plasma concentrations, are relevant to assessing potential user risk.

Of the eight substances tested (Table 2), two were shown to exceed the sensor bias limit at test concentrations that were equal to or less than literature-reported therapeutic concentrations, indicating that they might interfere with sensor readings when used at clinically relevant doses; these were tetracycline and mannitol (which exceeded the bias limit at the low but not the high glucose test concentration).

\section{Discussion}

This study showed that among the 41 substances screened at supraphysiologic/supratherapeutic plasma levels in vitro, eight were identified as possible interferents for glucose measurements by the Eversense CGM sensor. A subsequent in vitro dose-response study showed that only two substances (tetracycline and mannitol) interfered when tested at plasma concentrations associated with therapeutic uses. Although the Eversense CGM sensor is implanted into subcutaneous tissue beneath the skin, and thus is exposed to ISF and not blood, specific ISF concentrations of tetracycline or mannitol have not been reported in the literature. Therefore, the literature-reported plasma values were used as exemplary maximum ISF concentrations. For exogenous compounds, interstitial concentrations are sometimes equal to but are most often less than those seen in the plasma. ${ }^{37}$ Therefore, the use of reference plasma levels represents "worst case" values in the context of this study, and substances that do not interfere with sensor function when used at reference plasma levels are unlikely to interfere with sensor function in the interstitial space. Since the worst-case tetracycline level did afford significant bias in this study, Eversense CGM users should be cautioned against the use of tetracyclines and should consider other antibiotics instead.

Sugar alcohols (e.g., sorbitol, xylitol, and mannitol) are used as sweeteners in food products that are often targeted to people with diabetes, as their ingestion results in lower increases in serum glucose levels than the ingestion of conventional sweeteners. The FDA recommends testing of glucose measurement devices at sugar alcohol concentrations of $0.09 \mathrm{mg} / \mathrm{dL}^{10}$ as these levels reflect those potentially resulting from normal dietary consumption of these food products. In this study, none of the sugar alcohols were identified as interferents when tested at that concentration. However, mannitol combined with sorbitol is also used as an irrigation solution during therapeutic transurethral procedures, and use of this solution has been clinically demonstrated to result in plasma concentrations significantly $>0.09 \mathrm{mg} / \mathrm{dL} .{ }^{38}$ The data in this study suggest that mannitol exceeds the ISO interference bias threshold at concentrations that may be achieved from therapeutic use of this irrigation solution. Given the structural similarity between sorbitol and mannitol, it is prudent to expect that sorbitol will have an interfering effect similar to mannitol. Therefore, Eversense CGM System users should be cautioned against therapeutic uses of irrigation solutions that contain either of those substances.

Table 2. Regression Analysis to Determine Substance Concentrations Required to Reach INTERNATIONAL ORGANIZATION FOR STANDARDIZATION INTERFERING EFFECT BIAS LiMITS and Comparison with Therapeutic Plasma or Interstitial Reference Concentrations

\begin{tabular}{|c|c|c|c|c|}
\hline \multirow[b]{2}{*}{ Substance } & \multicolumn{2}{|c|}{$\begin{array}{l}\text { Concentration required to reach } \\
\text { ISO bias limit }(\mathrm{mg} / \mathrm{dL})\end{array}$} & \multirow{2}{*}{$\begin{array}{c}\text { Therapeutic } \\
\text { concentrations from the } \\
\text { literature }(\mathrm{mg} / \mathrm{dL})\end{array}$} & \multirow{2}{*}{$\begin{array}{l}\text { Bias limits } \\
\text { exceeded } \\
\text { at therapeutic } \\
\text { concentrations }\end{array}$} \\
\hline & Low glucose & High glucose & & \\
\hline L-DOPA & 0.24 & 0.46 & $0.05^{50}, 0.08$ in interstitial fluid $^{51}$ & No \\
\hline Lactate & $>75$ (test limit) & 75 & $4.5-20^{27}$ & No \\
\hline Mannitol & 5.6 & 23 & 34 in serum ${ }^{38}$ & Yes \\
\hline Piroxicam & 1.08 & 1.46 & 0.12 in $\operatorname{ISF}^{52,53}$ & No \\
\hline Pralidoxime iodide (PAM) & 30.7 & 31.4 & 3.8 in blood ${ }^{44}$ & No \\
\hline Ribose & $>140$ (test limit) & 61 & 32 in plasma ${ }^{48}$ & No \\
\hline Salicylic acid & 7.5 & 7.6 & 0.95 in interstitial fluid ${ }^{54}$ & No \\
\hline Tetracycline & a & 0.23 & $0.2-0.5^{27}$ & Yes \\
\hline
\end{tabular}

\footnotetext{
${ }^{a}$ Test results at the high glucose concentration clearly established bias that exceeded within the therapeutic range; therefore, no further tests were conducted.

ISF, interstitial fluid; ISO, International Organization for Standardization.
} 
Of note, acetaminophen and ascorbic acid did not appear to have any significant effect on Eversense CGM sensor bias within the in vitro screening study. This contrasts with the known effect of these substances on other commercially available sensors. Indeed, Basu et al. $^{39}$ reported for the Dexcom Seven Plus, Medtronic Diabetes Guardian, and Dexcom G4 Platinum CGM systems that a single 1-g dose of acetaminophen in participants who had plasma glucose levels of $90 \mathrm{mg} / \mathrm{dL}$ had sensor measurements that varied over a wide range $(85-400 \mathrm{mg} / \mathrm{dL})$. Similarly, FDA-approved package labeling indicates that acetaminophen affects the sensor accuracy of the Dexcom G5 Mobile CGM System, ${ }^{40}$ whereas salicylic acid and ascorbic acid affect the sensor accuracy of the Freestyle Libre. ${ }^{41}$ Investigators have suggested that acetaminophen and ascorbic acid likely interfere with the electrochemical detection elements (i.e., working electrodes) of those sensors-a mechanism that is qualitatively different from the abiotic, fluorescent glucose-indicating mechanism of the Eversense CGM sensor. Therefore, the lack of interference by these substances may provide an advantage offered by the Eversense CGM System when compared with electrochemical-based CGM systems.

In this study, compounds were selected so as to cover a range of structural classifications. Thus, levofloxacin, piroxicam, tetracycline, and quinidine were tested so as to span the range of wavelengths that may pose potential interference with the fluorescent Eversense sensor. Although it should be recognizable that their test results with these substances cannot be extrapolated to all drugs that fluoresce or that may interfere with signaling through other mechanisms (e.g., fluorescence quenching), these selected compounds were useful in identifying a potential risk area (i.e., compounds that may absorb or fluoresce light across the same wavelength range as tetracycline). Similarly, a wide range of compounds with vicinal diol moieties (i.e., monosaccharides, disaccharides, polysaccharides, sugar alcohols, catechols, alphahydroxy carboxylic acids, and aminosugars) were tested to assess the risks of cross-reactivity (vicinal diols are structurally related to glucose); testing revealed a potential risk of cross-reactivity from sugar alcohols at concentrations associated with use of intraoperative irrigation solutions but not at concentrations expected from dietary consumption of these substances. Other classes of compounds frequently prescribed to people with diabetes, such as antihypertensives (e.g., angiotensin-converting enzyme inhibitors, beta blockers, and diuretics) and hypoglycemics (e.g., sodium-glucose cotransporter 2 inhibitors and glucagon-like peptide-1 agonists), are examples of rational candidates for future interference tests.

A notable limitation inherent to an in vitro test of a sensor that is intended for subcutaneous implantation is the use of literature-reported plasma concentrations as representative of "worst-case" ISF concentrations for many of the compounds tested. As mentioned previously, this limitation stems from the absence of literature-reported ISF concentrations for those compounds. The actual concentration of a compound in the subdermal ISF relative to plasma is dependent on drug distribution to the subcutaneous tissue, which, in turn, varies according to the substance's water and lipid solubility and extent of protein binding. Furthermore, use of combinations of drugs that have synergistic or additive pharmacokinetic and/or interference effects may alter those concentrations and/or sensor function, respectively. Consequently, testing was performed at concentrations that are in excess (typically threefold) of maximum literature-reported plasma concentrations, as shown in Table 1, to increase the probability that the concentrations tested are beyond the maximum expected ISF concentrations.

Although in vitro interference tests, such as that used in this study, are not surrogates for in vivo (animal or clinical) investigations, they remain useful tools for the identification and assessment of potential risks and can help guide future studies and the design of new glucose sensors.

\section{Conclusions}

The interference profile of the Eversense CGM System is markedly different from enzymatic, electrochemical-based transcutaneous CGM systems. Several substances reported to interfere with those systems (i.e., ascorbic acid, acetaminophen, dopamine, maltose, and xylose) did not affect Eversense readings. However, mannitol and tetracycline exceeded interference test limits at therapeutic concentrations.

\section{Acknowledgments}

The authors thank Lynne Kelley, MD, FACS, for valuable discussions throughout the writing of this article. This study was funded by Senseonics, Inc. (Germantown, MD).

\section{Author Disclosure Statement}

All the authors are employees of Senseonics, Inc., and have stock options or own stock in the company.

\section{References}

1. Parkin CG, Graham C, Smolskis J: Continuous glucose monitoring use in type 1 diabetes: longitudinal analysis demonstrates meaningful improvements in HbAlc and Reductions in health care utilization. J Diabetes Sci Technol 2017;11:522-528.

2. Battelino T, Conget I, Olsen B, et al.: The use and efficacy of continuous glucose monitoring in type 1 diabetes treated with insulin pump therapy: a randomised controlled trial. Diabetologia 2012;55:3155-3162.

3. Beck RW, Riddlesworth T, Ruedy K, et al.: Effect of continuous glucose monitoring on glycemic control in adults with type 1 diabetes using insulin injections: the DIAMOND randomized clinical trial. JAMA 2017;317:371-378.

4. Abraham MB, de Bock M, Paramalingam N, et al.: Prevention of insulin-induced hypoglycemia in type 1 diabetes with predictive low glucose management system. Diabetes Technol Ther 2016;18:436-443.

5. Pickup JC, Freeman SC, Sutton AJ: Glycaemic control in type 1 diabetes during real time continuous glucose monitoring compared with self monitoring of blood glucose: meta-analysis of randomised controlled trials using individual patient data. BMJ 2011;343:d3805.

6. El-Laboudi AH, Godsland IF, Johnston DG, et al.: Measures of glycemic variability in type 1 diabetes and the effect of real-time continuous glucose monitoring. Diabetes Technol Ther 2016;18:806-812.

7. Litchman ML, Allen NA: Real-time continuous glucose monitoring facilitates feelings of safety in older adults with type 1 diabetes: a qualitative study. J Diabetes Sci Technol 2017;11:988-995. 
8. Polonsky WH, Hessler D: What are the quality of life-related benefits and losses associated with real-time continuous glucose monitoring? A survey of current users. Diabetes Technol Ther 2013;15:295-301.

9. Ginsberg BH: Factors affecting blood glucose monitoring: sources of errors in measurement. J Diabetes Sci Technol 2009;3:903-913.

10. U.S. Food and Drug Administration (FDA): Blood glucose monitoring test systems for prescription point-of-care use: guidance for industry and Food and Drug Administration staff. Issued on October 11, 2016. www.fda.gov/downloads/ medicaldevices/deviceregulationandguidance/guidance documents/ucm380325.pdf (accessed March 6, 2017).

11. Sylvester EC, Price CP, Burrin JM: Investigation of the potential for interference with whole blood glucose strips. Ann Clin Biochem 1994;31(Pt 1):94-96.

12. Basu A, Slama MQ, Nicholson WT, et al.: Continuous glucose monitor interference with commonly prescribed medications: a pilot study. J Diabetes Sci Technol 2017;11: 936-941.

13. Maahs DM, DeSalvo D, Pyle L, et al.: Effect of acetaminophen on CGM glucose in an outpatient setting. Diabetes Care 2015;38:e158-e159.

14. Abbott Laboratories, Inc. FreeStyle Libre Pro: Contraindications. www.freestylelibrepro.us. Accessed January 12, 2018.

15. Erbach M, Freckmann G, Hinzmann R, et al.: Interferences and limitations in blood glucose self-testing: an overview of the current knowledge. J Diabetes Sci Technol 2016;10: 1161-1168.

16. Pfützner A, Demircik F, Sachsenheimer D, et al.: Impact of xylose on glucose-dehydrogenase-based blood glucose meters for patient self-testing. J Diabetes Sci Technol 2017;11: 577-583.

17. Gardiner P, Graham RE, Legedza ATR, et al.: Factors associated with dietary supplement use among prescription medication users. Arch Intern Med 2006;166:1968-1974.

18. Hensrud DD, Engle DD, Scheitel SM: Underreporting the use of dietary supplements and nonprescription medications among patients undergoing a periodic health examination. Mayo Clin Proc 1999;74:443-447.

19. Fosnocht D, Taylor JR, Caravati EM: Emergency department patient knowledge concerning acetaminophen (paracetamol) in over-the-counter and prescription analgesics. Emerg Med J 2008;25:213-216.

20. Wilcox CM, Cryer B, Triadafilopoulos G: Patterns of use and public perception of over-the-counter pain relievers: focus on nonsteroidal antiinflammatory drugs. J Rheumatol 2005;32:2218-2224.

21. Christiansen MP, Klaff LJ, Brazg R, et al.: PRECISE II pivotal trial of a long term implantable CGM system: 90 days of sustained accuracy and strong safety profile. Proceedings and Abstracts of the 10th International Conference on Advanced Technologies and Treatments for Diabetes (ATTD), February 15-18, 2017, Paris, France [Abstract \#096].

22. Kropff J, Choudhary P, Neupane S, et al.: Accuracy and longevity of an implantable continuous glucose sensor in the precise study: a 180-day, prospective, multicenter, pivotal trial. Diabetes Care 2017;40:63-68.

23. Macrury S, Srinivasan A, Mahoney JJ: Performance of a new meter designed for assisted monitoring of blood glucose and point-of-care testing. J Diabetes Sci Technol 2013;7:389-398.
24. Tang Z, Du X, Louie RF, et al.: Effects of drugs on glucose measurements with handheld glucose meters and a portable glucose analyzer. Am J Clin Pathol 2000;113: 75-86.

25. Bailey T, Chang A, Rosenblit PD, et al.: A comprehensive evaluation of the performance of the test strip technology for OneTouch Verio glucose meter systems. Diabetes Technol Ther 2012;14:701-709.

26. Mortellaro M, DeHennis A: Performance characterization of an abiotic and fluorescent-based continuous glucose monitoring system in patients with type 1 diabetes. Biosens Bioelectron 2014;61:227-231.

27. Clinical and Laboratory Standards Institute (CLSI): Interference Testing in Clinical Chemistry; Approved GuidelineSecond Edition. CLSI document EP7-A2. Wayne: Clinical and Laboratory Standards Institute, 2005. http://shop.clsi.org/ method-evaluation-documents/EP07.html (accessed March 6, 2017).

28. James TD, Phillips MD, Shinkai S: Boronic Acids in Saccharide Recognition. Royal Society of Chemistry, Cambridge, UK, 2006.

29. Albert-Garcia JR, Antón-Fos GM, Duart MJ, et al.: Theoretical prediction of the native fluorescence of pharmaceuticals. Talanta 2009;79:412-418.

30. American Diabetes Association: Pharmacologic approaches to glycemic treatment. Diabetes Care 2017;40(Suppl 1): S64-S74.

31. Lucarelli F, Ricci F, Caprio F, et al.: GlucoMen Day continuous glucose monitoring system: a screening for enzymatic and electrochemical interferents. J Diabetes Sci Technol 2012;6:1172-1181.

32. International Organization for Standardization (ISO): ISO 15197:2013: In vitro diagnostic test systems: requirements for blood-glucose monitoring systems for self-testing in managing diabetes mellitus. ISO; 2013. www.iso.org/standard/ 54976.html (accessed March 6, 2017).

33. Wang X, Mdingi C, DeHennis A, et al.: Algorithm for an implantable fluorescence based glucose sensor. Conf Proc IEEE Eng Med Biol Soc 2012;2012:3492-3495.

34. Dehennis A, Mortellaro MA, Ioacara S: Multisite study of an implanted continuous glucose sensor over 90 days in patients with diabetes mellitus. J Diabetes Sci Technol 2015;9:951-956.

35. Fogh-Andersen N, Altura BM, Altura BT, et al.: Composition of interstitial fluid. Clin Chem 1995;41:1522-1525.

36. Haaverstad R, Romslo I, Larsen S, et al.: Protein concentration of subcutaneous interstitial fluid in the human leg. A comparison between the wick technique and the blister suction technique. Int J Microcirc Clin Exp 1996;16:111117.

37. Chisholm GD, Waterworth PM, Calnan JS, Garrod LP: Concentration of antibacterial agents in interstitial tissue fluid. Br Med J 1973;1:569-573.

38. Renner F, Schmitz A, Gehring H: Rapid and sensitive gas chromatography-mass spectroscopy method for the detection of mannitol and sorbitol in serum samples. Clin Chem 1998;44:886-887.

39. Basu A, Veettil S, Dyer R, et al.: Direct evidence of acetaminophen interference with subcutaneous glucose sensing in humans: a pilot study. Diabetes Technol Ther 2016; 18(Suppl 2):S243-S247.

40. U.S. Food and Drug Administration (FDA): Approved products: G5 Mobile. www.accessdata.fda.gov/cdrh_docs/ pdf12/P120005S041C.pdf (accessed January 12, 2018). 
41. U.S. Food and Drug Administration (FDA): Approved products: Freestyle Libre. www.accessdata.fda.gov/cdrh_ docs/pdf16/P160030C.pdf (accessed January 12, 2018).

42. Khor SP, Hsu A: The pharmacokinetics and pharmacodynamics of levodopa in the treatment of Parkinson's disease. Curr Clin Pharmacol 2007;2:234-243.

43. O'Connell MT, Tison F, Quinn NP, et al.: Clinical drug monitoring by microdialysis: application to levodopa therapy in Parkinson's disease. Br J Clin Pharmacol 1996; 42765-769.

44. Eddleston M, Eyer P, Worek F, et al.: Pralidoxime in acute organophosphorus insecticide poisoning - a randomised controlled trial. PLoS Med 2009;6:e1000104.

45. Welling PG, Patel RB, Patel UR, et al.: Bioavailability of tolazamide from tablets: comparison of in vitro and in vivo results. J Pharm Sci 1982;71:1259-1263.

46. Davies D: Kinetics of icodextrin. Perit Dial Int 1994; 14(Suppl 2):S45-S50.

47. Etchison JR, Freeze HH: Enzymatic assay of D-mannose in serum. Clin Chem 1997;43:533-538.

48. Gross M, Zöllner N: Serum levels of glucose, insulin, and c-peptide during long-term d-ribose administration in man. Klin Wochenschr 1991;69:31-36.

49. Craig RM, Murphy P, Gibson TP, et al. Kinetic analysis of D-xylose absorption in normal subjects and in patients with chronic renal failure. J Lab Clin Med 1983;101:496-506.
50. Dizdar N, Kullman A, Norlander B, et al.: Human pharmacokinetics of L-3,4-dihydroxyphenylalanine studied with microdialysis. Clin Chem 1999;45:1813-1820.

51. Dizdar N, Granérus AK, Hannestad U, et al.: L-dopa pharmacokinetics studied with microdialysis in patients with Parkinson's disease and a history of malignant melanoma. Acta Neurol Scand 1999;100:231-237.

52. Scheja A, Forsgren A, Ohlsson K, Wollheim FA: Reduced in vivo leucocyte migration and elastase and lysozyme concentrations in skin chamber experiments with piroxicam in healthy volunteers. Clin Exp Rheumatol 1986;4:43-47.

53. Bannwart B, Bertin P, Péhourcq F, et al.: Piroxicam concentrations in plasma and synovial fluid after a single dose of piroxicam-beta-cyclodextrin. Int J Clin Pharmacol Ther 2001;39:33-36.

54. Benfeldt E, Serup J, Menné T: Microdialysis vs. suction blister technique for in vivo sampling of pharmacokinetics in the human dermis. Acta Derm Venereol 1999;79:338-342.

Address correspondence to:

Carrie Lorenz, PhD

Senseonics, Incorporated

20451 Seneca Meadows Parkway

Germantown, MD 20876

E-mail: carrie.lorenz@senseonics.com 